\title{
Altered Consciousness Associated with Chronic Liver Disease
}

CrossMark

\author{
Ali Ghavidel 1,*, Amirhossein Ghavidel ${ }^{2}$
}

1. Assistant Professor, Liver and Gastrointestinal Diseases Research Centre, Imam Reza Hospital, Tabriz University of Medical Sciences, Tabriz, Iran

2. Medical student, Tabriz University of Medical Sciences, Tabriz, Iran

* Corresponding Author:

Ali Ghavidel, MD

Liver and Gastrointestinal Diseases Research Center, Imam Reza Hospital Tabriz University of Medical Sciences, Daneshgah Ave, Tabriz, Iran Telefax: + 984133347554 Email: ghavidela@tbzmed.ac.ir

Received: 09 Aug. 2018

Accepted: 22 Nov. 2018
Please cite this paper as:

Ghavidel A, Ghavidel AH. Altered Consciousness Associated with Chronic Liver Disease. Middle East J Dig Dis 2019:11:55-58. doi: 10.15171/mejdd.2018.129.

A 58-year-old woman came to clinic suffering from a headache, which started suddenly, and also had right hemiparesis. The patient felt drowsy while being admitted. She had no history of head trauma, but had history of chronic liver dysfunction, with a low blood platelet count. She was also suffering from cirrhosis since 5 years earlier and her liver disorder was diagnosed as autoimmune hepatitis (AIH). With probable diagnosis of hepatic encephalopathy, certain laboratory evaluations, such as alanine and aspartate aminotransferases (ALT and AST), blood glucose level, hemoglobin and blood platelet count, as well as the prothrombin time (PT, INR) are requested. Laboratory results show that blood glucose level is over $120 \mathrm{mg} / \mathrm{dL}$, hemoglobin level is $9.4 \mathrm{~g} / \mathrm{dL}$, blood platelet count is $(54,000 / \mu \mathrm{L})$. Prothrombin time (PT, INR) was 24.5 seconds or so called $\% 28$. This patient also suffers from moderate/severe leukocytosis that can be related to acute stress or infection. The amounts of urea and creatinine are also above normal levels, which can be a sign of pre-renal azotemia or hepato-renal syndrome. The amounts of direct and indirect bilirubin are increased noticeably, specially the direct fraction kind, which might show inter-hepatic cholestasis. These results can be seen in table 1 .

Hepato-biliary sonography demonstrated that the size of liver was smaller than normal, and it was hyperechogen, but internal and external biliary ducts, as well as the gall-bladder were normal.

In order to find out why the patient had consciousness problems, brain computed tomography (CT) was done, and multiple thin slices on different levels of the brain were illustrated. These radiographic scans are all presented as figure 1 below. As you can see, there is a mixed hypo- and hyper-dense lesion at the right hemisphere, which applies pressure to the brain's middle line, and therefore, causing hyper intra-cranial pressure. And the right lateral ventricle has disappeared. Also, there are calcifications in both lateral ventricles, which are considered to be normal.

Due to the results mentioned above, neurosurgical consultation was requested for the patient, in order to reduce the intra-cranial pressure.

Our patient's relatives did not consent for surgical intervention, so the patient passed away. 
Table 1: Laboratory results

\begin{tabular}{|c|c|c|c|}
\hline Test & Result & Unit & Reference value \\
\hline W.B.C & $23.8 \mathrm{H}$ & $\mathrm{x} 1000 / \mathrm{mm}^{3}$ & $4.0-11$ \\
\hline R.B.C & $3.80 \mathrm{~L}$ & $\mathrm{X} 10^{\wedge} 6 / \mathrm{mm}^{3}$ & M:4.5 - 5.8; F:4 - 5.2 \\
\hline $\mathrm{Hb}$ & $9.4 \mathrm{~L}$ & $\mathrm{gm} / \mathrm{dl}$ & M:14 - 18; F:12 - 16 \\
\hline Het & $33.5 \mathrm{~L}$ & $\%$ & M: $39-52 ; \mathrm{F}: 36-46$ \\
\hline Platelet & $54 \mathrm{~L}$ & $\mathrm{x} 1000 / \mathrm{mm}^{3}$ & $150-450$ \\
\hline INR & 2.84 & Index & $0.9-1.0$ \\
\hline PT & $24.5 \mathrm{H}$ & Sec. & Up to 12.9 \\
\hline PT Activity & $28 \mathrm{~L}$ & $\%$ & $70-100$ \\
\hline Blood sugar & 125 & $\mathrm{mg} / \mathrm{dl}$ & $70-110$ \\
\hline Urea & $168 \mathrm{H}$ & $\mathrm{mg} / \mathrm{dl}$ & M:19 - 44; F:15 - 40 \\
\hline Creatinine & $2.64 \mathrm{H}$ & $\mathrm{mg} / \mathrm{dl}$ & $0.7-1.4$ \\
\hline SGOT (AST) & $44 \mathrm{H}$ & IU/L & M:0 - 31; F:0 - 37 \\
\hline SGPT(ALT) & 18 & $\mathrm{IU} / \mathrm{L}$ & M:0 - 41; F:0 - 31 \\
\hline Alk. P & $4173 \mathrm{H}$ & $\mathrm{IU} / \mathrm{L}$ & Adult:64 - 306; Children:180 - 1200 \\
\hline Total Bili. & $33.5 \mathrm{H}$ & $\mathrm{mg} / \mathrm{dl}$ & Adult:0.1 - 1.2; Childern:0.1 - 12.6 \\
\hline Direct Bili. & $24.4 \mathrm{H}$ & $\mathrm{mg} / \mathrm{dl}$ & $0-0.4$ \\
\hline Indirect Bili. & $9.1 \mathrm{H}$ & $\mathrm{Mg} / \mathrm{dl}$ & $0.1-0.8$ \\
\hline Albumin & $2.2 \mathrm{~L}$ & $\mathrm{~g} / \mathrm{dl}$ & $3.5-5.2$ \\
\hline Amylase & $210 \mathrm{H}$ & $\mathrm{IU} / \mathrm{L}$ & Up to 100 \\
\hline Serum $\mathrm{Na}$ & $130 \mathrm{~L}$ & $\mathrm{mEq} / \mathrm{L}$ & $136-145$ \\
\hline Potassium & 4.3 & $\mathrm{mEq} / \mathrm{L}$ & $3.6-5$ \\
\hline Lipase & 18 & $\mathrm{IU} / \mathrm{L}$ & Up to 60 \\
\hline CTNI & Negative & $\mathrm{ng} / \mathrm{ml}$ & Up to 0.3 \\
\hline
\end{tabular}

White blood cells (WBC), Red blood cells (RBC), Hemoglobin (Hb), Hematocrit (Hct), Prothrombin Time (PT), International Normalized Ratio (INR), Serum Glutamic-Pyruvic Transaminase (SGPT), Serum Glutamic-Oxaloacetic Transaminase (SGOT), Alkaline phosphatase (Alk.P), Total Bilirubin (Total Bili), Direct Bilirubin (Direct Bili) Indirect Bilirubin (Indirect Bili), Serum Sodium (Serum Na) Cardiac-specific Troponin I (CTNI)

A second CT after 48 hours revealed left acute subdural hematoma and a shift in the midline structures.

\section{What is your diagnosis?}

\section{Acute spontaneous subdural hematoma}

Patients with chronic liver disease and a severe hemostatic syndrome and altered consciousness, should be investigated with $\mathrm{CT}$ to diagnose probable intracerebral hemorrhage and hematoma as soon as possible. An important laboratory alarming signal could be a noticeable decrease in blood platelet count and a prolonged prothrombin time. Chronic liver diseases are considered to be important risk factors for neurosurgical complications such as subdural hematoma and intracerebral hemorrhage.

\section{DISCUSSION}

For the first time, Huang $\mathrm{HH}$ et al. ${ }^{1}$ presented a few patients with acute spontaneous subdural hematoma at the beginning of the $21^{\text {st }}$ century, with an average age of 53 years (ranged between 32 and 82). Surgical findings showed that the bleeding points were mostly in the cortical arteries located near the sylvian fissure. Eventually, one of the patients recovered, one had a minor defect, and two had major defects. They believed that an early surgical operation was required for a fine prognosis.

Grønbæk $\mathrm{H}$ et al. ${ }^{2}$ reported that in patients with chronic liver diseases with increased risk of intracerebral hemorrhage, fatality rate was lower than the control group (the group without liver dysfunction). They claimed that the feature that makes the bleeding in patients with liver disorders different from others, was the bleeding location. ${ }^{3,4}$ They also mentioned that as the patients developed more neurological complications, their prognoses were worse.

Wilberger and others ${ }^{5}$ analyzed the results of 4515 hospital inpatients with cirrhosis, and found acute spon- 

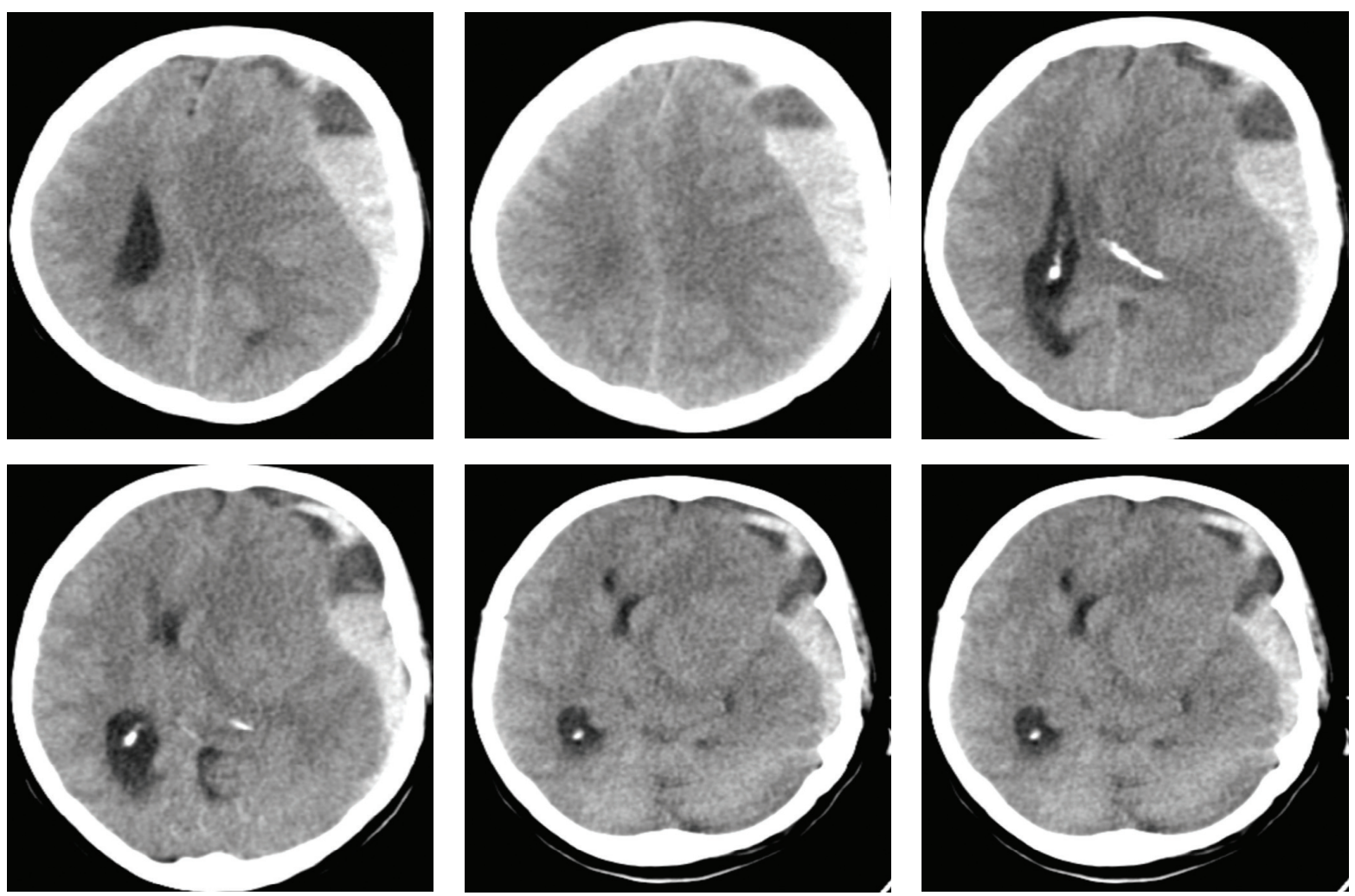

Fig.1: Computed tomography of the case

taneous subdural hematoma in 36 patients who had no history of stroke, head injuries, or cerebral arteriovenous malformations. They concluded that the patients' variables, including the cause of chronic liver disease, severity of cirrhosis, and bleeding site, can affect the prognosis.

Lai and colleagues ${ }^{6}$ found that acute spontaneous subdural hematoma is seen in $1-2 \%$ of the patients with liver cirrhosis, with the relative risk of almost one and a half. Their conclusion was that patients with liver cirrhosis had an increased incidence rate of acute spontaneous subdural hematoma compared with the general population.

\section{CONCLUSION}

Patients with chronic liver disease and a severe hemostatic syndrome and altered consciousness, should be investigated with CT in order to diagnose probable intracerebral hemorrhage and hematoma as soon as possible. An important laboratory alarming signal could be a noticeable decrease in blood platelet count and a prolonged PT. Chronic liver diseases are considered to be important risk factors for neurosurgical complications such as subdural hematoma and intracerebral hemorrhage.

\section{ETHICAL APPROVAL}

There is nothing to be declared.

\section{CONFLICT OF INTEREST}

The authors declare no conflict of interest related to this work.

\section{REFERENCES}

1. Huang HH, Lin HH, Shih YL, Chen PJ, Chang WK, Chu $\mathrm{HC}$, et al. Spontaneous intracranial hemorrhage in cirrhotic patients. Clin Neurol Neurosurg 2008;110:253-8. doi: 10.1016/j.clineuro.2007.11.010.

2. Grønbæk H, Johnsen SP, Jepsen P, Gislum M, Vilstrup H, Tage-Jensen U, et al. Liver cirrhosis, other liver diseases, and risk of hospitalization for intracerebral haemorrhage: A Danish population-based case-control study. BMC Gastroenterol 2008;8:16. doi:10.1186/1471-230X-8-16.

3. Hoya K, Tanaka Y, Uchida T, Takano I, Nagaishi M, Kowata $\mathrm{K}$, et al. Intracerebral hemorrhage in patients with chronic liver disease. Neurol Med Chir (Tokyo) 2012;52:181-5. doi:10.2176/nmc.52.181. 
4. Depreitere B, Van Calenbergh F, van Loon J. A clinical comparison of non-traumatic acute subdural haematomas either related to coagulopathy or of arterial origin without coagulopathy. Acta Neurochir (Wien) 2003;145:541-6. doi: 10.1007/s00701-003-0020-7.

5. Wilberger JE. Pathophysiology of evolution and recurrence of chronic subdural hematoma. Neurosurg Clin $N$ Am 2000;11:435-8. doi:10.1016/S1042-3680(18)30105-0.

6. Lai CH, Cheng PY, Chen YY. Liver cirrhosis and risk of intracerebral hemorrhage: a 9-year follow-up study. Stroke 2011;42:2615-7. doi:10.1161/STROKEAHA.111.617076. 